\title{
Phylogenetic and metabolic diversity of Tunisian forest wood-degrading fungi: a wealth of novelties and opportunities for biotechnology
}

\author{
Dalel Daâssi ${ }^{1,2} \cdot$ Héla Zouari-Mechichi ${ }^{1} \cdot$ Lassaad Belbahri $^{3,4} \cdot$ Jorge Barriuso $^{5}$. \\ María Jesús Martínez ${ }^{5} \cdot$ Moncef Nasri $^{1}$ • Tahar Mechichi ${ }^{1}$
}

Received: 1 November 2015/ Accepted: 24 December 2015/Published online: 4 February 2016

(C) The Author(s) 2016. This article is published with open access at Springerlink.com

\begin{abstract}
In this study, 51 fungal strains were isolated from decaying wood samples collected from forests located in the Northwest of Tunisia in the vicinity of Bousalem, Ain Draham and Kef. Phylogenetic analysis based on the sequences of the internal transcribed spacers of the ribosomal DNA showed a high diversity among the 51 fungal isolates collection. Representatives of 25 genera and 29 species were identified, most of which were members of one of the following phyla (Ascomycota, Basidiomycota and Zygomycota). In addition to the phylogenetic diversity, a high diversity of secreted enzyme profiles was also detected among the fungal isolates. All fungal strains
\end{abstract}

Dalel Daâssi and Héla Zouari-Mechichi have contributed equally to this work.

Electronic supplementary material The online version of this article (doi:10.1007/s13205-015-0356-8) contains supplementary material, which is available to authorized users.

Dalel Daâssi

daleldaassi@yahoo.com

Tahar Mechichi

tahar.mechichi@enis.rnu.tn

1 Laboratory of Enzyme Engineering and Microbiology, Ecole Nationale d'Ingénieurs de Sfax, University of Sfax, Route de Soukra Km 4,5, BP 1173, 3038 Sfax, Tunisia

2 Department of Biology, Faculty of Sciences and Arts, Khulais, University of Jeddah, Jeddah, Saudi Arabia

3 Laboratory of Soil Biology, University of Neuchatel, Rue Emile Argand 11, 2009 Neuchâtel, Switzerland

4 NextBiotech, Agareb, Tunisia

5 Centro de Investigaciones Biológicas (CIB-CSIC), Ramiro de Maeztu 9, 28040 Madrid, Spain produced at least one of the following enzymes: laccase, cellulase, protease and/or lipase.

Keywords Isolation - Wood degrading fungi - Enzyme activities $\cdot$ Laccase $\cdot$ Biotechnological application

\section{Introduction}

Wood is the most abundant biopolymer in nature and is made up mainly of cellulose, hemicellulose, and lignin. The lignin polymer is highly recalcitrant toward chemical and biological degradation due to its molecular architecture, where different non-phenolic phenylpropanoid units forming a complex three-dimensional network, are interconnected by a variety of ether and carbon-carbon bonds. Its biodegradation is a key step for carbon recycling in terrestrial ecosystems.

A number of. microorganisms including bacteria and filamentous fungi are able to degrade lignocellulosic components to various extents (Eriksson et al. 1990; RuizDueñas and Martínez 2009). Fungi participating in plant cell wall deconstruction include white rot, brown rot and leaf litter fungi (Cho et al. 2009).

The white rot fungi are the most studied because they are the unique organisms able to mineralize cell wall components with high lignin content, producing a bleached aspect of decayed wood in nature (Taylor 1995; Sigoillot et al. 2012). This ability is related to their production of a nonspecific system, including several extracellular enzymes, low molecular weight metabolites and activated oxygen species (Schoemarker 1990; Dashtban et al. 2010; Choi et al. 2012). It is worth mentioning that this system is also involved in the degradation of aromatic recalcitrant compounds causing environmental problems (Schoemarker et al. 1991; Reddy 1995). 
In this sense, ligninolytic enzymes have been involved in the degradation of xenobiotic and recalcitrant aromatic compounds, industrial dyes (Khlifi et al. 2009; Daâssi et al. 2012), polycyclic aromatic hydrocarbons (PAHs) (Lee et al. 2013), pesticides (Xiao et al. 2011), dioxins (Sato et al. 2002), chlorophenols (Li et al. 2011), explosives (Cheong et al. 2006) and kraft pulp bleaching (Moldes et al. 2010).

The enzymes involved in lignin degradation include laccases, different types of peroxidases and oxidases producing $\mathrm{H}_{2} \mathrm{O}_{2}$ (Shimada and Higuchi 1991, Martínez et al. 2009). The most widely studied ligninolytic enzymes are, lignin peroxidase (LiP), Mn-dependent peroxidase (MnP) and laccase (Lac) (Thurston 1994; Orth and Tien 1995) in contrast to the other high redox potential peroxidases, such as versatile peroxidase (VP) and dye decolorizing peroxidase (DyP, EC 1.11.1.19) (Martínez et al. 2009; Sugano 2009). The complete conversion of lignocellulose requires the hydrolysis of structural cell wall polysaccharides by carbohydrate-acting enzymes, such as cellulases and hemicellulases (Hatakka and Hammel 2010). In addition other complementary enzymes, such as esterases/lipases or proteases, could complement the enzymatic cocktails to completely transform wood biomass into product of biotechnological interest, such as animal feed, chemical products and/or biofuel (Leonowicz et al. 1999; Barriuso et al. 2013; Dashtban et al. 2010).

Although basidiomycetes have been the most commonly studied fungi as principal organisms involved in lignin biodegradation, Ascomycetes are also able to degrade cellulose and hemicellulose despite their limitation in lignin conversion (Martínez et al. 2005). Among these ascomycetes some pathogenic fungi, such as Fusarium solani, are able to degrade lignin and secrete laccases and lignin peroxidases (Obruca et al. 2012).

It is estimated that there are approximately 1.5 million fungal species in the world, of which only approximately $4.6 \%$ are described (Hawksworth, 2001). Given the wide diversity of the ligninolytic enzymes, the lignocellulosic degrading enzyme complex to which they belong and their dependence on the species and/or on the culture conditions (Hatakka, 1994; Peláez et al. 1995), the isolation and study of new ligninolytic fungi and their enzymes still receive huge interest for their putative biotechnological applications.

In this study, within the framework of a screening program of lignin microorganism degraders, we aimed to assess the fungal diversity of wood degraders in Tunisian forests. 51 new fungal species were isolated, identified, phylogenetically grouped and analyzed for their enzymes involved in biomass transformation (laccase, lipase, cellulase and protease activities).

\section{Materials and methods}

\section{Chemicals}

2,2'-Azino-bis(3-ethylbenzothiazoline-6-sulfonic acid) diammonium salt (ABTS) (cas: 30931-67-0), guaiacol (cas: 90-05-1) and the dyes: reactive black 5 (RB-5), Remazol Brilliant Blue R (RBBR) (cas: 2580-78-1) and Blue Turquoise (GL) (cas: 1330-38-7) were obtained from SigmaAldrich (Tunis, Tunisia).

\section{Collection of fungi}

Pieces of decaying wood were collected from different habitats of the Northwest region of Tunisia (forests of Ain Draham, Bousalem and Kef) during the winters of (2009-2010) and 2011 to isolate wood-degrading fungal strains. Samples were transported in sterilized plastic bags and brought to the laboratory without further exposure to the external environment. The samples were marked with relevant information, such as number, location, and specific characteristics.

\section{Isolation of fungal strains}

Fungal strains were isolated using a selective agar media composed of Malt Extract (ME) (30 g/L, pH 5.5) supplemented with antibiotics (ampicillin and streptomycin at $0.01 \%$ ) to avoid bacterial growth (Kiiskinen et al. 2002). The samples were surface sterilized by drying under a laminar flow hood and squares of approximately $3 \times 3 \mathrm{~mm}$ were placed on selective agar media. The plates were subsequently incubated at $30{ }^{\circ} \mathrm{C}$. Later on, when the mycelium had grown on the solid media, the samples were transferred to fresh agar media in Petri-dishes. This was repeated until pure cultures could be obtained as single cultures or so-called fungal isolates. Qualitative screening method for enzyme production was carried out by inoculation of $1 \mathrm{~cm}$ diameter pieces of mycelium from each strain onto the specific medium for the given enzyme activity.

\section{Enzyme activity detection in solid media}

Enzymatic activities were analyzed in plates and the fungal isolates classified as positive or negative, correlated with the presence or the absence of the halo surrounding mycelium growth. To determine the activity of each isolated strain, inoculations were made in triplicate, taking a fraction (approx. $0.5 \mathrm{~cm}^{2}$ ) of the mycelium under aseptic conditions and placing it in the center of the plate containing the corresponding medium for the enzymatic 
activity analyzed. Then, they were incubated at $30{ }^{\circ} \mathrm{C}$ until the activity recorded.

\section{Detection of protease activity}

The proteolytic activity of fungal isolates was tested on a milk nutrient agar medium. The medium contained 3 and $5 \mathrm{~g} / \mathrm{L}$ yeast extract and peptone, respectively. The $\mathrm{pH}$ was then adjusted to 5.5 and the medium supplemented with $15 \mathrm{~g} / \mathrm{L}$ agar.

After sterilization, $250 \mathrm{~mL}$ of sterile milk were added to the medium. After mixing the medium was poured into Petri dishes. The activity was determined by measuring the halo formed by the degraded milk proteins (Mayerhofer et al. 1973).

\section{Detection of CMCase activity}

Cellulolytic activity was detected on agar plates supplemented with $1 \mathrm{~g} / \mathrm{L}$ of carboxymethylcellulose (CMC). The screening medium contained $(\mathrm{g} / \mathrm{L})$ : yeast extract $(1.0)$, $\mathrm{K}_{2} \mathrm{HPO}_{4}$ (2.0), $\mathrm{KH}_{2} \mathrm{PO}_{4}$ (1.0), $\mathrm{MgSO}_{4}$ (1.0) $\mathrm{MnSO}_{4}(0.4)$, $\mathrm{FeSO}_{4}(0.01)$ and $\left(\mathrm{NH}_{4}\right)_{2} \mathrm{SO}_{4}(3.0)$. The $\mathrm{pH}$ of the medium was then adjusted to 5.5. The plates were incubated at $30{ }^{\circ} \mathrm{C}$ and after growth, they were washed with Congo red and distained with $1 \mathrm{M} \mathrm{NaCl}$. In positive samples a hydrolyzed zone appears transparent while the non hydrolyzed regions appeared bright red. The presence of a clear zone around the isolate demonstrated that the tested isolate produced cellulolytic enzymes (Sakthivel et al. 2010).

\section{Detection of lipolytic activity}

Rhodamine B and olive oil agar plates (ME (30 g/L), $1 \%$ olive oil, $0.001 \%$ rhodamine B (Sigma, Tunis, Tunisia), and $1.5 \%$ agar (Difco, Tunis, Tunisia) were used for the detection of lipase activity. After 7 days of incubation at $30{ }^{\circ} \mathrm{C}$, the culture plates were revealed under $365 \mathrm{~nm}$ light and the activity was determined by visual evaluation of fluorescence intensity (Kouker and Jaeger 1987).

\section{Detection of amylase activity}

The screening procedure for amylase activity detection was based on a plate culture method which uses soluble starch $(1 \%)$ as carbon source. The screening plate medium contained (g/L): yeast extract (1.0), $\mathrm{K}_{2} \mathrm{HPO}_{4}(2.0), \mathrm{KH}_{2}$ $\mathrm{PO}_{4}$ (1.0), $\mathrm{MgSO}_{4}$ (1.0) $\mathrm{MnSO}_{4}(0.4), \mathrm{FeSO}_{4}$ (0.01) and $\left(\mathrm{NH}_{4}\right)_{2} \mathrm{SO}_{4}$ (3.0). The $\mathrm{pH}$ of the medium was adjusted to 5.5 by using $12 \mathrm{~N} \mathrm{HCl}$. The medium was sterilized by autoclaving at $121{ }^{\circ} \mathrm{C}$ for $20 \mathrm{~min}$. Fungi were placed on the agar medium and incubated at $30{ }^{\circ} \mathrm{C}$ for 7 days. Starch degrading fungi were identified based of the formation of clear zones after exposure with Lugol's iodine solution ( $1 \%$ iodine; $2 \%$ potassium iodide w/v). Diameters of clear zones and fungal colonies were evaluated by a millimeter ruler (Singh and Modi 2013).

\section{Detection of laccase and ligninase activities}

\section{Primary screening: culture on solid media}

To assess laccase activity, ME medium (30 g/L, $18 \mathrm{~g} / \mathrm{L}$ agar) containing $4 \mathrm{mM}$ guaiacol or $2 \mathrm{mM}$ ABTS $\left(2,2^{\prime}\right.$ azino-di-3-ethylbenzotiazol-6-sulfonate acid) supplemented with $0.15 \mathrm{mM} \mathrm{CuSO}_{4}$ was used. Incubation of plates was performed at $30^{\circ} \mathrm{C}$. Positive laccase activity was identified by the formation of reddish brown halo in guaiacol and greenish-colored halo in ABTS supplemented plates. Observations were carried out by measuring the diameter of ring-shaped mycelia (Gnanasalomi and Gnanadoss 2013). The diameter of the halo indicated the level of laccase activity produced.

Ligninase activity was assayed based on the decolorization of different families of textile dyes such as remazol brilliant blue (RBBR), reactive black 5 (RB5) and turquoise blue (GL) (phthalocyanine). ME medium (30, $18 \mathrm{~g} / \mathrm{L}$ agar) containing $150 \mathrm{mg} / \mathrm{L}$ of dye was used. Decolorization in a solid medium was assessed by visual disappearance of color from the plate (Selvam et al. 2012; Zouari-Mechichi et al. 2006).

\section{Secondary screening: cultures on liquid media}

The quantitative determination of laccase activity, ABTS and guaiacol oxidizing strains were grown in $500 \mathrm{~mL}$ Erlenmeyer flasks containing 100 mL M7 medium. Each flask was inoculated with three cylindrical plugs $(4 \mathrm{~mm}$ in diameter) of active mycelia from previously cultured in ME agar and incubated at $30{ }^{\circ} \mathrm{C}, 150 \mathrm{rpm}$ for 20 days. Sampling was done at regular intervals and centrifuged at $8000 \mathrm{rpm},+4{ }^{\circ} \mathrm{C}$ for $10 \mathrm{~min}$. The supernatants were used to measure laccase activities. All the experiment was carried out in duplicates.

\section{Laccase activity assay}

Spectrophotometric assays of laccase activity were carried out with $1 \mathrm{mM}$ guaiacol or $10 \mathrm{mM}$ 2,2'-azino-bis-(3ethylbenzthiazolinesulphonate) (ABTS) as substrates, in $100 \mathrm{mM}$ sodium acetate buffer ( $\mathrm{pH}$ 5.0). When guaiacol was used, the absorbance was monitored at $465 \mathrm{~nm}$ ( $\varepsilon=12,000 \mathrm{M}^{-1} \mathrm{~cm}^{-1}$ ); when ABTS was the substrate, the absorbance was monitored at $436 \mathrm{~nm}(\varepsilon=$ 29,300 $\mathrm{M}^{-1} \mathrm{~cm}^{-1}$ ) (Silva et al. 2005). 


\section{Identification of fungal isolates by sequencing the ITS region}

Each isolate was cultivated in a $100 \mathrm{~mL}$ flask containing $25 \mathrm{~mL}$ of liquid ME medium for 5 days. Then mycelium was collected, washed with sterile Milli-Q water and lyophilized.

The molecular identification was carried out with the protocol presented by Daâssi et al. (2013). The primers used for the amplification were ITS1 (5'-TCCGTAGGTGAACCTGCGG- $3^{\prime}$ ) and ITS4 (5'-TCCTCCGCTTATTGATATGC-3') (White et al., 1990). Sequencing was performed using an automated ABI Prism 3730 DNA sequencer (Applied Biosystems, Tunis, Tunisia).

\section{DNA sequence and phylogenetic analysis}

The resulting sequences were subjected to BlastN analysis (www.ncbi.nlm.nih.gov/BlastN). The organisms were identified relying on the sequences available in the database presenting the highest homology. The sequences from the different isolated strains and those from the GenBank were aligned using CLUSTAL W (Thompson et al. 1994). Distances were calculated and phylogenetic trees were constructed using the neighbour-joining method (Saitou and Nei, 1987). Bootstrap analysis was done based on 1000 replicates. The MEGA3 package was used for all analyses. Sequences have been deposited in GenBank. Genbank accession numbers will be provided later.

\section{Results and discussion}

\section{Isolation and identification of fungi isolated from Tunisian forests}

The isolation experiments resulted in fifty-one fungal isolates. The internal transcribed spacer (ITS) regions of fungal rDNA have been successfully used for species identification (Table 1). The fungal strains isolated during this work were found to be highly diverse based on the ITS genetic marker (Table 2). The capacity of the isolates to produce laccases, lipases, proteases, amylases, and cellulolytic enzymes was investigated on selective solid media (Table 3).

The levels of similarity (Table 1) allowed us to assign all fungal isolates to the genus or even the species level according to Rossello Mora and Amman (2001) except few isolates such as isolate CLBE 24 that matched an undescribed uncultured fungus. The 51 fungal isolates belong to 22 genera and 34 species (Table 2). Ascomycete fungi of the genera: Phoma (single strain), Ilyonectria (1 strain), Coniochaeta (3 strains), Neurospora (1 strain),
Trichoderma (7 strains), Spencermartinsia (1 strain), Fusarium (6 strains), Alternaria (4 strains), Thermomyces (6 strains), Preussia (1 strain), Cladosporium (1 strain), Paecilomyces (1 strain), and Pyronellaea (1 strain), basidiomycetes of the genera: Trametes (1 strain), Coriolopsis (4 strains), Phanerochaete (3 strains), Ganoderma (1 strain), Bjerkandera (2 strains), Gloeophyllum (2 strains), Prosterium (1 strain) and Perenniporia (1 strain) and Mucoromycetes of the genus Mucor (1 strain), were identified and studied in detail.

\section{Secreted enzymatic activities}

All 51 isolates were screened by plate test methods for laccases, proteases, amylases, cellulases, and lipases production. Data presented in Table 3 shows that among the tested isolates, 32 strains were found to produce laccases, 25 strains were found to produce cellulases, 18 strains were found to produce amylases, 21 strains were found to produce proteases and 27 strains were found to produce lipases. Therefore, the results of enzymes screening (Table 3) show a high diversity of enzymatic activities in the fungi isolated from Tunisian forests. Several studies reported that ligninolytic fungi use a combination of several activities (hydrolases, oxidoreductases and esterases) for wood degradation indicating the complexity of the ligninocellulosic materials (Yoon et al. 2007; Ljungdahl 2008; Dashtban et al. 2010).

\section{Protease activity producing fungi}

Table 3, clearly shows that protease activity is revealed principally in basidiomycete taxa, including fungi from Trametes, Ganoderma and Phanerochaete genera although ascomycete fungi, from Ilyonectria genus, were able to produce this activity. While, the presence of extracellular proteases in basidiomycete fungi, such as Coriolopsis trogii (Caporale et al. 1996) and Trametes versicolor (Staszczak and Nowak, 1984), has been well known for decades, their occurrence in Phanerochaete chrysosporium is a current topic of interest (Dass et al. 1995; Xiong et al. 2008). These authors investigated the effect of nitrogen excess/limitation culture conditions on the expression of proteases and peroxidases in $P$. chrysosporium. They reported that the wood-degrading fungus $P$. chrysosporium produces proteolytic activity associated to excess nitrogen conditions (non-ligninolytic conditions). However, when subjected to nitrogen limitation, Phanerochaete produces principally peroxidases to depolymerize lignin in wood. These studies provide clues to optimize extracellular enzymes production by fungi in synthetic media for biotechnological applications. 
Table 1 Blast report showing the accession no and total score query coverage max identity

\begin{tabular}{|c|c|c|c|c|}
\hline No. & Strain & Molecular identification & Accession No & Max identity (\%) \\
\hline 1 & BS54 & Coriolopsis gallica & gblAY684172.1l & 99 \\
\hline 2 & BS2 & Phanerochaete chrysosporium & gb|JQ796876.1। & 100 \\
\hline 3 & $\mathrm{BS} 22$ & Coriolopsis trogii & gblHM989941.1l & 99 \\
\hline 4 & TM11 & Bjerkandera adusta & gblFJ608590.1l & 99 \\
\hline 5 & BS17 & Byssochlamys spectabilis & gblFJ895878.1l & 100 \\
\hline 6 & BS34 & Ganoderma carnosum & gb|JQ520163.1l & 99 \\
\hline 7 & D11 & Trichoderma harzianum & gblHQ596939.1l & 100 \\
\hline 8 & D6 & Ilyonectria destructans & emblAJ875317.1l & 99 \\
\hline 9 & BS14 & Coniochaeta sp. & gb|JN225913.1l & 99 \\
\hline 10 & BS19 & Neurospora sp. & gb|JF749204.1l & 99 \\
\hline 11 & 11B & Bjerkandera adusta & gblJF439464.1l & 99 \\
\hline 12 & A3 & Trametes versicolor & gb|KC492579.1। & 94 \\
\hline 13 & BS56 & Trichoderma citrinoviride & gb|KC009820.1l & 100 \\
\hline 14 & $\mathrm{AD} 40$ & Coriolopsis trogii & gb|JN164998.1। & 98 \\
\hline 15 & $\mathrm{BS} 25$ & Porostereum spadiceum & gb|JX46661.1l & 80 \\
\hline 16 & CLBE1 & Phoma macrostoma & gblJF723492.1l & 82 \\
\hline 17 & CLBE2 & Spencermartinsia viticola & gblAY905555.1l & 100 \\
\hline 18 & CLBE3 & Fusarium solani & gblEU750688.1l & 99 \\
\hline 19 & CLBE4 & Fusarium oxysporum & gblAF322074.1l & 100 \\
\hline 20 & CLBE5 & Fusarium equiseti & gblEU326202.1l & 99 \\
\hline 21 & CLBE6 & Alternaria tenuissima & gb|EU326185.1l & 100 \\
\hline 22 & CLBE9 & Peyronellaea glomerata & gblAY183371.1l & 100 \\
\hline 23 & CLBE10 & Trichoderma gamsii & gb|JQ040342.1l & 100 \\
\hline 24 & CLBE11 & Fusarium equiseti & gblAY147362.1l & 100 \\
\hline 25 & CLBE12 & Alternaria alternata & gb|GQ121322.2| & 99 \\
\hline 26 & CLBE13 & Trichoderma harzianum & gblEU280078.1l & 99 \\
\hline 27 & CLBE14 & Mucor racemosus & gblHM641690.1। & 99 \\
\hline 28 & CLBE15 & Gloeophyllum trabeum & emblAJ420949.1l & 99 \\
\hline 29 & CLBE16 & Gloeophyllum trabeum & emblAJ420949.1l & 99 \\
\hline 30 & CLBE17 & Alternaria sp. & gblEF432274.1l & 100 \\
\hline 31 & CLBE18 & Trichoderma harzianum & gblEU280078.1l & 100 \\
\hline 32 & CLBE19 & Fusarium equiseti & gblEU326202.1l & 100 \\
\hline 33 & CLBE20 & Trichoderma viride & gblAF455432.1l & 99 \\
\hline 34 & CLBE24 & Uncultured fungus. & emb|FN689670.1 & 99 \\
\hline 35 & CLBE29 & Thermomyces lanuginosus & dbj|AB085929.1l & 100 \\
\hline 36 & CLBE33 & Fusarium solani & gblJQ277276.11) & 99 \\
\hline 37 & CLBE35 & Thermomyces lanuginosus & dbjlAB085929.1l & 94 \\
\hline 38 & CLBE40 & Thermomyces lanuginosus & dbj|AB085929.1l & 100 \\
\hline 39 & CLBE41 & Thermomyces lanuginosus & dbj|AB085929.1l & 100 \\
\hline 40 & CLBE44 & Thermomyces lanuginosus & dbjlAB085929.1l & 100 \\
\hline 41 & CLBE47 & Thermomyces lanuginosus & gblJQ639282.1 & 99 \\
\hline 42 & CLBE49 & Coniochaeta sp. & gb|JN225913.1। & 99 \\
\hline 43 & CLBE50 & Preussia minima & gblDQ468027.1। & 99 \\
\hline 44 & CLBE51 & Cladosporium cladosporioides & gb|JX981454.1l & 99 \\
\hline 45 & CLBE53 & Coniochaeta sp. & gb|JN225913.1l & 99 \\
\hline 46 & CLBE54 & Perenniporia medulla-panis & gb|JQ673013.1l & 99 \\
\hline 47 & CLBE55 & Coriolopsis trogii & gblHM989941.1। & 100 \\
\hline 48 & CLBE56 & Phanerochaete chrysosporium & dbj|AB361644.1l & 99 \\
\hline
\end{tabular}


Table 1 continued

\begin{tabular}{lllll}
\hline No. & Strain & Molecular identification & Accession No & Max identity (\%) \\
\hline 49 & CLBE57 & Phanerochaete chrysosporium & gb|KP135093.1। & 99 \\
50 & CLBE58 & Alternaria brassicae & gb|JX290150.1। & 99 \\
51 & CLBE59 & Trichoderma harzianum & gb|JF923802.1। & 99 \\
\hline
\end{tabular}

Table 2 Number of fungal genera and species among different taxonomic groups in Tunisian forests and their relative load (\%)

\begin{tabular}{|c|c|c|c|c|c|}
\hline Phylum & Orders & Number of isolates & Number of genera & Number of species & Load \% \\
\hline Uncultured fungus & - & 1 & 1 & 1 & 2 \\
\hline Mucoromycotina & Mucorales & 1 & 1 & 1 & 2 \\
\hline \multirow[t]{7}{*}{ Ascomycetes } & Coniochaetales & 3 & 1 & 1 & 6 \\
\hline & Pleosporales & 7 & 3 & 8 & 14 \\
\hline & Capnodiales & 1 & 1 & 1 & 2 \\
\hline & Eurotiales & 7 & 2 & 2 & 14 \\
\hline & Botryosphaeriales & 1 & 1 & 1 & 2 \\
\hline & Sordiariales & 1 & 1 & 1 & 8 \\
\hline & Hypocreales & 14 & 3 & 8 & 27 \\
\hline \multirow[t]{2}{*}{ Basidiomycetes } & Polyporales & 13 & 7 & 8 & 25 \\
\hline & Gloeophyllales & 2 & 1 & 2 & 4 \\
\hline Total number of isolates & - & 51 & 25 & 29 & 100 \\
\hline Load \% & - & 100 & 49 & 57 & \\
\hline
\end{tabular}

\section{Lipase activity producing fungi}

Lipolytic activity has been studied in the isolates collection. The results (Table 3) reveal a relevant capacity of the tested fungi to secrete lipase, making their further study very interesting. Among the tested strains, 27 lipase-producing fungi were detected within ascomycete group, such as Thermomyces, Fusarium and Neonectria. In Fusarium and Thermomyces the capacity to synthesize this type of enzymes is well characterized (Jallouli et al. 2012; Kovalenko et al. 2013). Our Results also agree with those of Cruz-Ramírez et al. (2012), where 49 lipase producing fungi have been recovered from a screening of fungal isolates from decaying wood samples collected in Mexico.

\section{Cellulase producing fungi}

Table 3 shows that among the 51 decay-wood fungi isolates, 25 strains present degradation halos reflecting a good activity on carboxymethylcellulose (CMCase) activity, indicating that this fungus is able to secrete a high $\beta-1,4-$ endoglucanase activity. It is well known that fungal lignin degradation involves lignocellulolytic enzymes such as CMCases to degrade lignocellulosic components in wood. CMCases are important enzymes necessary for the degradation of cellulose and have been reported from well- known strains of Trichoderma and Paecilomyces (Colussi et al. 2011; Hussain et al. 2012). The ability of these fungal strains to degrade lignocellulosic biomass, as well as their utility in treatments of pulp and paper mill effluent, have been mentioned in many reports (Hussain et al. 2012). In addition to CMCase other cellulolytic enzymes such as cellobiohydrolases were shown to be also secreted simultaneously in Trichoderma harzianum IOC 3844 (de Castro et al. 2010; Colussi et al. 2011) and Paecilomyces variotii 103-7 isolated from naturally degraded wood (Hussain et al. 2012).

\section{Amylase producing fungi}

Amylase activity was detected in some members of the fungal collection and was present in $35 \%$ of the total isolates. P. variotii and Neurospora sp. were good producers of amylases (Table 3). In the same trend, Michelin et al. (2010) reported the purification of a thermostable $\alpha$ amylase produced by the fungus $P$. variotti.

\section{Laccase producing fungi}

Wood decay fungi are a very good source of lignin enzymes typically phenol oxidases (laccases). Data presented in Table 3 show that of the 51 tested strains, 31 
Table 3 Screening of guaiacol-oxidation activity and molecular identification for different isolates

\begin{tabular}{|c|c|c|c|c|c|c|c|}
\hline \multirow[t]{2}{*}{ No. } & \multirow[t]{2}{*}{ Strains } & \multicolumn{5}{|c|}{ Enzymatic activities } & \multirow[t]{2}{*}{ Molecular identification } \\
\hline & & $\mathrm{Lac}^{1}$ & $\mathrm{CMCas}^{2}$ & $\operatorname{Prot}^{3}$ & Amyl $^{4}$ & $\operatorname{Lip}^{5}$ & \\
\hline 1 & BS54 & +++ & ++ & - & ++ & + & Coriolopsis gallica \\
\hline 2 & BS2 & ++ & - & - & ++ & - & Phanerochaete chrysosporium \\
\hline 3 & $\mathrm{BS} 22$ & ++ & + & + & ++ & - & Coriolopsis trogii \\
\hline 4 & TM11 & +++ & - & + & - & - & Bjerkandera adusta \\
\hline 5 & BS17 & + & +++ & - & +++ & - & Byssochlamys spectabilis \\
\hline 6 & BS34 & +++ & - & + & - & - & Ganoderma carnosum \\
\hline 7 & D11 & - & ++ & - & - & - & Trichoderma harzianum \\
\hline 8 & D6 & + & ++ & +++ & + & +++ & Ilyonectria destructans \\
\hline 9 & BS14 & + & ++ & +++ & - & - & Coniochaeta sp. \\
\hline 10 & BS19 & + & ++ & - & +++ & + & Neurospora sp. \\
\hline 11 & $11 \mathrm{~B}$ & +++ & + & - & - & + & Bjerkandera adusta \\
\hline 12 & A3 & +++ & & & - & - & Trametes versicolor \\
\hline 13 & BS56 & - & +++ & - & - & - & Trichoderma citrinoviride \\
\hline 14 & AD40 & +++ & - & + & ++ & - & Coriolopsis trogii \\
\hline 15 & BS25 & +++ & + & - & ++ & - & Porostereum spadiceum \\
\hline 16 & CLBE1 & + & - & + & - & + & Phoma macrostoma \\
\hline 17 & CLBE2 & + & + & - & - & + & Spencermartinsia viticola \\
\hline 18 & CLBE3 & - & + & - & - & + & Fusarium solani \\
\hline 19 & CLBE4 & - & + & - & - & +++ & Fusarium oxysporum \\
\hline 20 & CLBE5 & - & + & - & - & +++ & Fusarium equiseti \\
\hline 21 & CLBE6 & - & - & + & + & + & Alternaria tenuissima \\
\hline 22 & CLBE9 & - & - & - & - & + & Peyronellaea glomerata \\
\hline 23 & CLBE10 & - & +++ & - & - & + & Trichoderma gamsii \\
\hline 24 & CLBE11 & - & - & + & - & +++ & Fusarium equiseti \\
\hline 25 & CLBE12 & - & + & - & - & - & Alternaria alternata \\
\hline 26 & CLBE13 & - & ++ & - & - & - & Trichoderma harzianum \\
\hline 27 & CLBE14 & ++ & - & - & - & - & Mucor racemosus \\
\hline 28 & CLBE15 & ++ & ++ & +++ & - & - & Gloeophyllum trabeum \\
\hline 29 & CLBE16 & ++ & ++ & +++ & + & - & Gloeophyllum trabeum \\
\hline 30 & CLBE17 & - & + & ++ & - & - & Alternaria sp. \\
\hline 31 & CLBE18 & - & ++ & - & + & - & Trichoderma harzianum \\
\hline 32 & CLBE19 & - & - & - & - & +++ & Fusarium equiseti \\
\hline 33 & CLBE20 & - & +++ & - & - & + & Trichoderma viride \\
\hline 34 & CLBE24 & - & - & - & - & - & Unculture fungus sp. \\
\hline 35 & CLBE29 & + & - & + & - & + & Thermomyces lanuginosus \\
\hline 36 & CLBE33 & - & - & - & + & + & Fusarium solani \\
\hline 37 & CLBE35 & ++ & - & - & - & + & Thermomyces lanuginosus \\
\hline 38 & CLBE40 & ++ & - & - & - & + & Thermomyces lanuginosus \\
\hline 39 & CLBE41 & ++ & - & - & - & - & Thermomyces lanuginosus \\
\hline 40 & CLBE44 & ++ & - & - & - & + & Thermomyces lanuginosus \\
\hline 41 & CLBE47 & - & - & + & + & + & Thermomyces lanuginosus \\
\hline 42 & CLBE49 & ++ & - & + & - & + & Coniochaeta sp. \\
\hline 43 & CLBE50 & - & + & - & - & + & Preussia minima \\
\hline 44 & CLBE51 & ++ & - & + & + & + & Cladosporium cladosporioides \\
\hline 45 & CLBE53 & ++ & - & + & - & - & Coniochaeta sp. \\
\hline 46 & CLBE54 & +++ & + & ++ & + & - & Perenniporia medulla-panis \\
\hline 47 & CLBE55 & ++ & - & + & - & - & Coriolopsis trogii \\
\hline
\end{tabular}


Table 3 continued

\begin{tabular}{|c|c|c|c|c|c|c|c|}
\hline \multirow[t]{2}{*}{ No. } & \multirow[t]{2}{*}{ Strains } & \multicolumn{5}{|c|}{ Enzymatic activities } & \multirow[t]{2}{*}{ Molecular identification } \\
\hline & & $\mathrm{Lac}^{1}$ & $\mathrm{CMCas}^{2}$ & $\operatorname{Prot}^{3}$ & $\mathrm{Amyl}^{4}$ & $\operatorname{Lip}^{5}$ & \\
\hline 48 & CLBE56 & + & - & - & + & ++ & Phanerochaete chrysosporium \\
\hline 49 & CLBE57 & ++ & - & ++ & + & + & Phanerochaete chrysosporium \\
\hline 50 & CLBE58 & ++ & - & + & + & + & Alternaria brassicae \\
\hline 51 & CLBE59 & - & ++ & - & - & - & Trichoderma harzianum \\
\hline
\end{tabular}

Lac, laccase activity; CMCase, cellulase activity; Prot, protease activity; Amyl, amylase activity; Lip, lipase activity

(+) Diameter of the halo surrounding mycelium growth 0-15 mm, (++) halo diameter 15-25 mm, (+++) halo diameter up to $25 \mathrm{~mm}$

exhibited significant guaiacol-oxidation activity expressed within the first week of incubation. Most of basidiomycetes were able to produce laccase and among them representatives of the genera Trametes, Phanerochaete, Ganoderma, Bjerkandera, and Porostereum were ranked as the best producers (Table 3 ). The basidiomycetous white-rot fungi are the most efficient lignin-degrading organisms in nature (Fackler et al. 2006).

\section{Primary screening: culture on solid media}

Fungi showing guaiacol-oxidation activities in Table 3 were cultivated on solid media containing $4 \mathrm{mM}$ guaiacol or $2 \mathrm{mM} \mathrm{ABTS}$ in the presence of $150 \mathrm{mM} \mathrm{CuSO}_{4}$ that enabled the detection of laccases as specific color reactions (Machado et al. 2005). Guaiacol and ABTS were considered as the best substrates for laccase activity (Thurston 1994).

The positive strains showed reddish brown halo in guaiacol supplemented agar and dark-green halo in ABTS supplemented plates (Fig. 1a). The diameter of the halo and the color intensity indicating a positive extracellular oxidoreductase secretion from mycelium was used to screen the level of laccase production of each strain (Table 4).

\section{Secondary screening: cultures on liquid media}

Laccase production by the fungal strains that were positive in the plate-test screening was further studied in liquid cultures.

Secondary screening experiments with the selected isolates showed that the activity of laccase was higher with ABTS than with guaiacol. Else, the highest levels of laccase production were produced by the basidiomycetous especially white-rot fungi which confirms the results find in the qualitative test. The white-rot basidiomycete $C$. trogii (CLBE55) was isolated from decayed acacia wood from North West of Tunisia and selected for its potential of laccase production (Zouari-Mechichi et al. 2006). These results are in agreement with those of Gnanasalomi and
Gnanadoss (2013) who reported the isolation of twenty-six basidomycetes that produce laccases.

As presented in Table 4, some fungal strains show laccase activity in a solid medium but not when cultured in a liquid medium. This may be explained by the need to create the proper conditions for laccase production for each isolate. In fact, the liquid medium (M7) was supported laccase production by basidiomycetes more than others taxonomic groups (Zouari-Mechichi et al. 2006). Some groups require such element in the cultures for laccase secretion.

A similar trend toward laccase activity dependence on the cultivation medium and conditions was reported by Kiiskinen et al. (2004) and Colao et al. (2003).

On the contrary Ryu et al. (2003) explain the observed difference between the revelation of laccase activity in solid and liquid medium by the fungal strains may have produced other ligninolytic enzymes.

To demonstrate the potential for biotechnological applications of our laccase producing fungi, we used them in further experiments to select ligninolytic fungal isolates able to decolorize and detoxify textile dyes, a relevant effluent produced by Tunisian textile industries and an important pollutant in natural ecosystems in Tunisia (Zouari-Mechichi et al. 2006).

\section{Laccase-producing fungi with potential for textile dye decolorization}

Ligninolytic systems, especially laccases, are directly involved in the degradation of various xenobiotic compounds and dyes. Their capacities to remove and decolorize dyes from textile industry effluents make them a useful tool for bioremediation purposes (Zouari-Mechichi et al. 2006).

As previously mentioned, $63 \%$ of laccase-producing fungi were found among the fungal isolates by qualitative test on plates. The ligninolytic activity of the 31 laccaseproducing fungi was further confirmed by their ability to oxidize three commercial industrial dyes (RBBR, RB-5 and GL) (Fig. 1b). It was observed that all screened isolates positive with guaiacol were able to oxidase RBBR and GL. 
Fig. 1 Photo of ME agar plate showing positive guaiacol, ABTS (a) and dyes (b) (GL, RB-5 and RBBR) oxidation by fungal isolates obtained from decayed wood samples after 7 days of inoculation $\mathbf{a}$
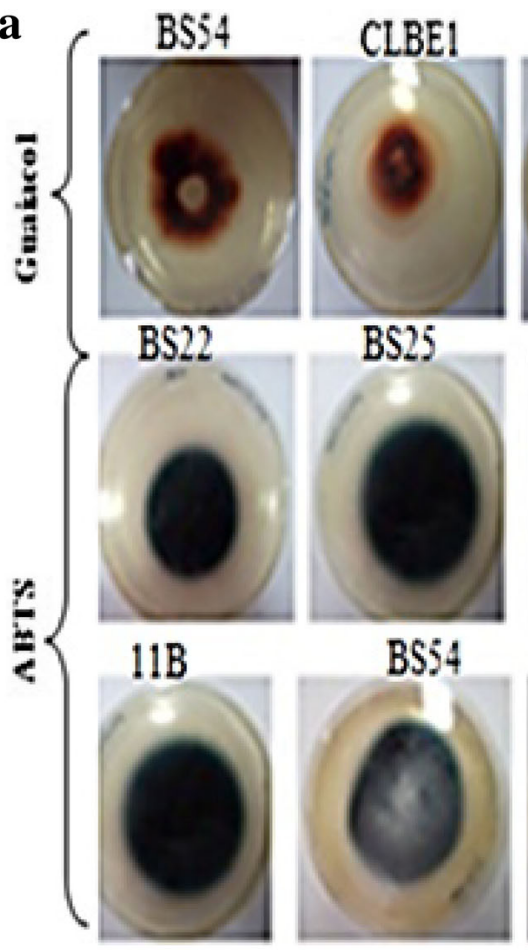

BS25

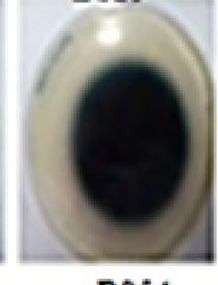

BS54
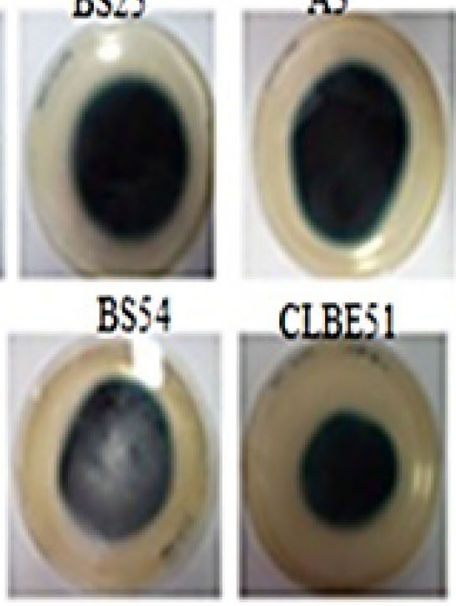

AD 40

BS22

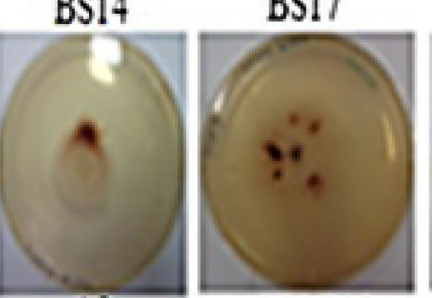

CBLES5

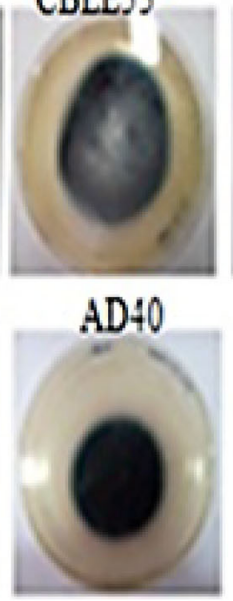

TMI1

b

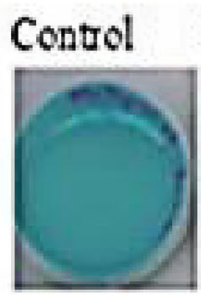

CLBE55
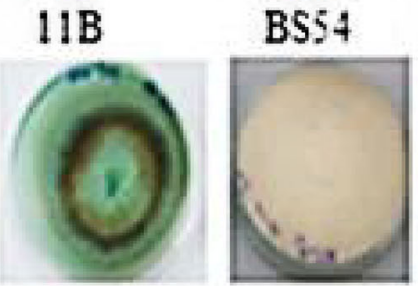

BS17
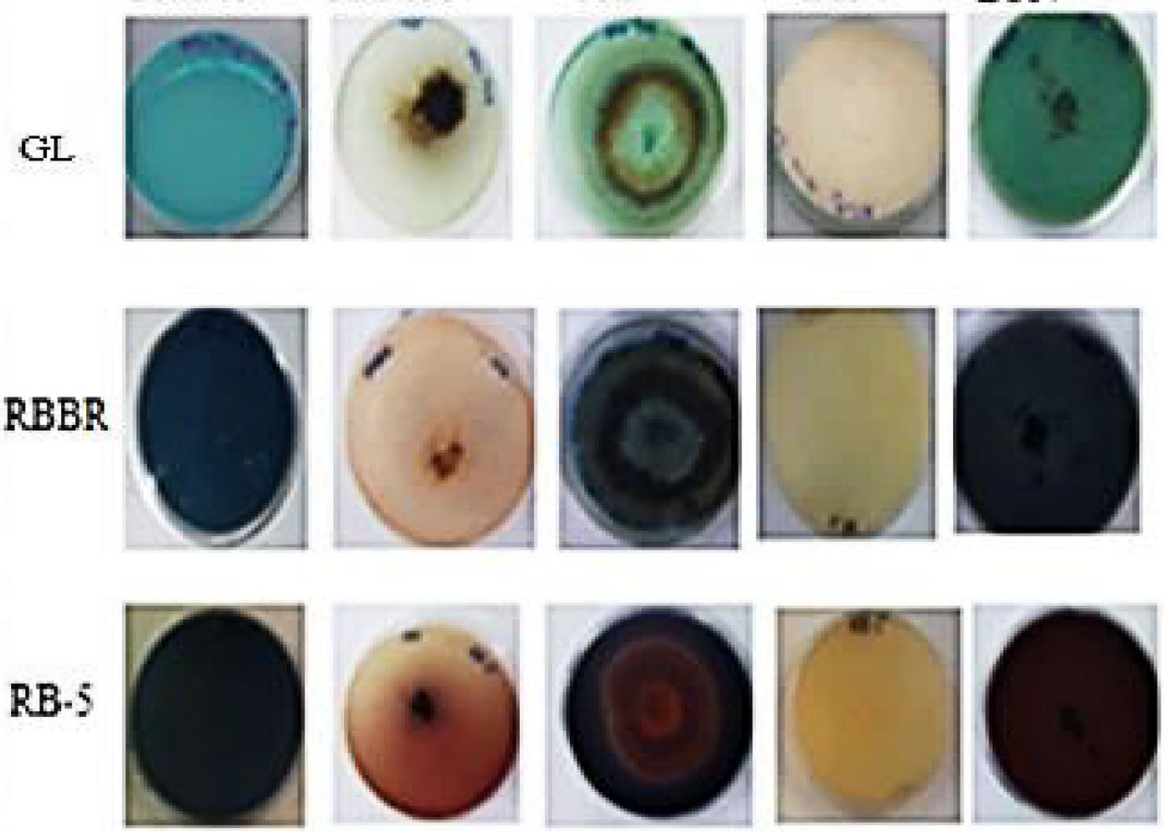

The correlation between the polymeric dyes and guaiacol was also good, as only one strain, BS17 (Byssochlamys spectabilis), was positive on guaiacol without being positive on polymeric dye indicators (Table 5). Our results suggest that color reactions with RBBR, GL and guaiacol are more easily detectable and these compounds can reliably be used for laccase activity screening. Moreover, strains able to oxidize the three dyes: anthraquinonic (RBBR), diazoic(RB-5) and phthalocyanine (GL), correlated well with each other in the oxidation of ABTS or guaiacol (diameter $>15 \mathrm{~mm}$ ). Some other strains were able to decolorize RBBR and GL but not RB-5 such as $T$. harzianum D11, Ilyonectria destructans D6, Coniochaeta sp. BS14, Phoma macrostoma CLBE1, Spencermartinsia 
Table 4 Qualitative test for Lac+ isolates using colored indicators (4 mM of guaiacol and $2 \mathrm{mM}$ of ABTS) and quantitative test in liquid M7 medium (with their $95 \%$ confidence limits; Mean \pm standard deviation $(n=3) ; 30{ }^{\circ} \mathrm{C} ; 150 \mathrm{rpm}$, in the presence of $\left.150 \mathrm{mM} \mathrm{CuSO}_{4}\right)$

\begin{tabular}{|c|c|c|c|c|c|}
\hline \multirow[t]{2}{*}{ No. } & \multirow[t]{2}{*}{ Strains } & \multicolumn{2}{|l|}{ Qualitative test } & \multicolumn{2}{|l|}{ Quantitative test } \\
\hline & & $\begin{array}{l}\text { Reddish-brown zone formation } \\
\text { (guaiacol) }\end{array}$ & $\begin{array}{l}\text { Green halo zone formation } \\
\text { (ABTS) }\end{array}$ & $\begin{array}{l}\text { Lac activity }(\mathrm{U} / \mathrm{L}) \text { with } \\
\text { guaiacol }\end{array}$ & $\begin{array}{l}\text { Lac activity (U/L) with } \\
\text { ABTS }\end{array}$ \\
\hline 1 & BS54 & +++ & ++ & $3880 \pm 12.2$ (9 day) & $4761 \pm 5.3$ (9 day) \\
\hline 2 & BS2 & ++ & +++ & ND & - \\
\hline 3 & $\mathrm{BS} 22$ & ++ & +++ & $1256 \pm 6.4$ (9 day) & $1443 \pm 3.5$ (9 day) \\
\hline 4 & TM11 & +++ & ++ & $4545 \pm 8.2$ (9 day) & $4914 \pm 4.7$ (9 day) \\
\hline 5 & BS17 & + & + & - & - \\
\hline 6 & BS34 & +++ & ++ & $1556 \pm 6.1$ (6 day) & $1788 \pm 7.2$ (6 day) \\
\hline 7 & D6 & + & + & $94 \pm 3.1$ (4 day) & $123 \pm 1.9(4$ day $)$ \\
\hline 8 & BS14 & + & + & $864 \pm 9.2(5$ day $)$ & $1127 \pm 6.8$ (5 day) \\
\hline 9 & BS19 & +++ & + & $122 \pm 3.6$ (9 day) & $165 \pm 1.9(9$ day $)$ \\
\hline 10 & $11 \mathrm{~B}$ & +++ & +++ & $8358 \pm 14.7$ (12 day) & $11,134 \pm 10.3$ (12 day) \\
\hline 11 & A3 & ++ & +++ & $5233 \pm 6.5$ (8 day) & $7064 \pm 9.1$ (8 day) \\
\hline 12 & $\mathrm{AD} 40$ & ++ & +++ & $4276 \pm 11.4$ (8 day) & $5855 \pm 6.7$ (8 day) \\
\hline 13 & BS25 & + & ++ & $1120 \pm 3.1$ (6 day) & $1252 \pm 1.9$ ( 6 day $)$ \\
\hline 14 & CLBE1 & ++ & ++ & $1944 \pm 5.7$ (6 day) & $2054 \pm 9.3$ ( 6 day $)$ \\
\hline 15 & CLBE2 & ++ & ++ & $2031 \pm 12.6(6$ day $)$ & $2645 \pm 10.5$ (6 day) \\
\hline 16 & CLBE14 & ++ & + & $723 \pm 5.3$ (6 day) & $789 \pm 2.3$ ( 6 day $)$ \\
\hline 17 & CLBE15 & + & & ND & ND \\
\hline 18 & CLBE16 & + & + & ND & ND \\
\hline 19 & CLBE29 & + & + & $22 \pm 9.6$ (6 day) & $88 \pm 1.3(6$ day $)$ \\
\hline 20 & CLBE35 & + & + & $34 \pm 2.3$ (4 day) & $54 \pm 6.4$ (4 day) \\
\hline 21 & CLBE40 & + & & $76 \pm 4.5$ (5 day) & $126 \pm 2.7(5$ day $)$ \\
\hline 22 & CLBE41 & ++ & + & $50 \pm 1.3(6$ day $)$ & $102 \pm 6.3(6$ day $)$ \\
\hline 23 & CLBE44 & ++ & + & $52 \pm 1.7$ (5 day) & $87 \pm 0.7$ (5 day) \\
\hline 24 & CLBE49 & +++ & + & $401 \pm 2.6$ (6 day) & $654 \pm 5.2(6$ day $)$ \\
\hline 25 & CLBE51 & ++ & + & $565 \pm 2.6$ (7 day) & $843 \pm 1.3$ (7 day) \\
\hline 26 & CLBE53 & ++ & + & $774 \pm 2.6$ (6 day) & $1123 \pm 5.5$ ( 6 day $)$ \\
\hline 27 & CLBE54 & +++ & + & $454 \pm 2.6(17$ day $)$ & $732 \pm 3.4(17$ day $)$ \\
\hline 28 & CLBE55 & +++ & +++ & $20,000 \pm 9.6(12$ day $)$ & $24,233 \pm 6.2(12$ day $)$ \\
\hline 29 & CLBE56 & + & + & ND & ND \\
\hline 30 & CLBE57 & + & + & ND & ND \\
\hline 31 & CLBE58 & + & + & $122 \pm 1.8$ (9 day) & $176 \pm 2.1(9$ day $)$ \\
\hline
\end{tabular}

$N D$ not detected laccase activity

(+) Diameter of the oxidized zone 0-15 mm, (++) zone diameter $15-25 \mathrm{~mm},(+++)$ zone diameter up to $25 \mathrm{~mm}$

viticola CLBE2, Gloeophyllum trabeum CLBE16, Thermomyces lanuginosus CLBE29, Perenniporia medullapanis CLBE54, Phanaerochaete chrysosporium CLBE56 and CLBE57 and Alternaria brassicae CLBE58. This correlates with the recalcitrant nature of RB-5 as diazoic dye and the need of system-laccase mediator (SLM) for RB-5 degradation as reported in many studies (Daâssi et al. 2012).

Decolorization of synthetic dyes has been demonstrated using white rot basidiomycetes (Diwaniyan et al. 2010; Daâssi et al. 2013) such as $P$. chrysosporium (Gomaa, 2012), Ganoderma sp. (Ma et al. 2014), Trametes trogii
(Zouari-Mechichi et al. 2006), Bjerkandera adusta (Choi et al. 2014) and Porostereum spadiceum (Tigini et al. 2013). Interestingly, our study shows the ability of some isolates belonging to ascomycete group to decolorize textile dyes. Only, few studies reported the capacity of ascomycetes in textiles dyes decolorization (Ashrafi et al. 2013).

\section{Taxonomical groups of lignin degrading fungi}

All taxa were taxonomically identified using BLAST and phylogenetic analysis, selecting matches with similarity 
Table 5 Comparison of reactions of the isolated fungal strains with different indicators (4 mM guaiacol and dyes: RBBR, RB-5 and GL) on malt extract agar plates

\begin{tabular}{|c|c|c|c|c|c|c|c|}
\hline \multirow[t]{2}{*}{ No. } & \multirow[t]{2}{*}{ Fungal isolates } & \multicolumn{3}{|c|}{ Mycelial growth and oxidation characteristics } & \multicolumn{3}{|c|}{ Oxidation of dyes } \\
\hline & & Colour zone diameter $(\mathrm{mm})^{\mathrm{a}}$ & Oxidation scale $^{\mathrm{b}}$ & Fungal colony diameter $(\mathrm{mm})^{\mathrm{c}}$ & RBBR & RB-5 & GL \\
\hline 1 & BS54 & 22 & ++ & 29 & $*$ & $*$ & $*$ \\
\hline 2 & BS2 & 21 & ++ & 30 & $*$ & $*$ & $*$ \\
\hline 3 & BS22 & 15 & ++ & 29 & $*$ & $*$ & $*$ \\
\hline 4 & TM11 & 21 & ++ & 18 & $*$ & $*$ & $*$ \\
\hline 5 & BS17 & 10 & + & 33 & - & - & - \\
\hline 6 & BS34 & 25 & +++ & 29 & $*$ & $*$ & $*$ \\
\hline 8 & D6 & 8 & + & 12 & $*$ & - & $*$ \\
\hline 9 & BS14 & 10 & + & 17 & $*$ & - & $*$ \\
\hline 10 & BS19 & 32 & +++ & 25 & $*$ & $*$ & $*$ \\
\hline 11 & $11 \mathrm{~B}$ & 31 & +++ & 30 & $*$ & $*$ & $*$ \\
\hline 12 & A3 & 21 & ++ & 29 & $*$ & $*$ & $*$ \\
\hline 13 & $\mathrm{AD} 40$ & 24 & ++ & 30 & $*$ & $*$ & * \\
\hline 14 & BS25 & 12 & + & 18 & $*$ & $*$ & $*$ \\
\hline 15 & CLBE1 & 15 & ++ & 20 & $*$ & - & $*$ \\
\hline 16 & CLBE2 & 18 & ++ & 25 & $*$ & - & $*$ \\
\hline 17 & CLBE14 & 21 & ++ & 27 & $*$ & $*$ & $*$ \\
\hline 18 & CLBE15 & 12 & + & 17 & $*$ & $*$ & $*$ \\
\hline 19 & CLBE16 & 10 & + & 18 & $*$ & - & $*$ \\
\hline 20 & CLBE29 & 14 & + & 19 & $*$ & - & $*$ \\
\hline 21 & CLBE35 & 12 & + & 18 & - & $*$ & - \\
\hline 22 & CLBE40 & 14 & + & 20 & - & $*$ & - \\
\hline 23 & CLBE41 & 18 & ++ & 22 & - & $*$ & - \\
\hline 24 & CLBE44 & 20 & ++ & 18 & $*$ & - & - \\
\hline 25 & CLBE49 & 21 & +++ & 25 & $*$ & $*$ & $*$ \\
\hline 26 & CLBE51 & 18 & ++ & 15 & $*$ & $*$ & $*$ \\
\hline 27 & CLBE53 & 16 & ++ & 24 & - & - & - \\
\hline 28 & CLBE54 & 32 & +++ & 24 & $*$ & - & $*$ \\
\hline 29 & CLBE55 & 22 & +++ & 14 & $*$ & $*$ & $*$ \\
\hline 30 & CLBE56 & 10 & + & 17 & $*$ & - & $*$ \\
\hline 31 & CLBE57 & 9 & + & 18 & $*$ & - & $*$ \\
\hline 32 & CLBE58 & 10 & + & 22 & $*$ & - & $*$ \\
\hline
\end{tabular}

${ }^{\text {a }}$ Diameter of the oxidized zone in mm (measured on the 7 th day of cultivation)

${ }^{b}$ Oxidation scale measured on the 7th day of cultivation on selective- medium containing $4 \mathrm{mM}$ guaiacol

c Diameter of the mycelial colony in mm measured on the 7th day of cultivation (the initial disc $10 \mathrm{~mm}$ diameter)

(+) Diameter of the oxidized zone 0-15 mm, (++) zone diameter 15-25 mm, (+++) zone diameter up to $25 \mathrm{~mm},(-)$ absence of clarified zone, (*) presence of clarified zone

higher than $98 \%$ to sequences in the GenBank database $(E$-value $<0.05)$. However, 3 taxa presented low matching similarity $(<98 \%)$. Those isolates that were identified with a similarity less than $98 \%$ were; CLBE 1 with $82 \%$ identity with $P$. macrostoma, A3 with $94 \%$ similarity to $T$. versicolor and BS25 with $80 \%$ similarity to $P$. spadiceum. CLBE 24 matched with $99 \%$ similarity an uncultured fungus not yet described (Table 1).

The 51 fungal isolates obtained in this study were classified into different taxa, representing 25 fungal genera and
29 species. Most of the isolates were found to belong to the phylum Ascomycota (67\%), some Basidiomycota (29\%) and only few Mucoromycotina (2\%) and non-identified uncultured fungi ( $2 \%$, Table 2). Ascomycetes found in this study derived from the orders Hypocraceales $(27 \%)$, Eurotiales (14\%), Pleosporales (14\% strains), Sordariales (2\%), Capnodiales (2\%), Coniochaetales $(6 \%)$ and Botryosphaeriales (2\%). Some researchers suggested a main contribution of ascomycetes in wood degradation (Nilsson and Daniel 1989; Michelotti et al. 2012). Guu et al. 
a

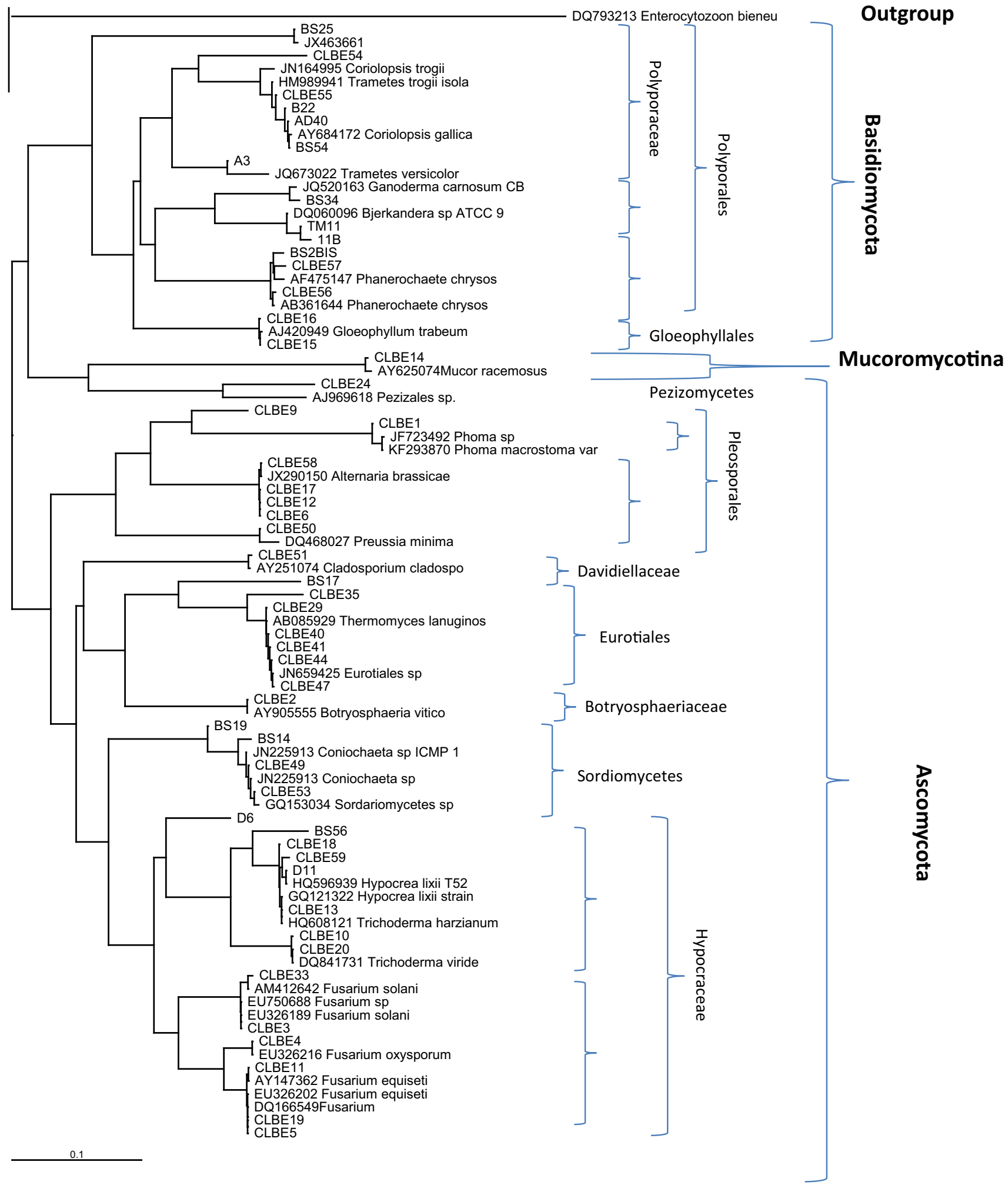

Fig. 2 Phylogenetic relationships of recovered fungi with selected database sequences based on ITS rDNA sequences. a The phylogram represents a maximum likelihood tree based on analyses of 43 taxa under the HKY model. b The tree was rooted with Microsporidia as outgroup. Bootstrap values higher than or equal to $50 \%$ (1000 replicates) are shown at each branches 


\section{b}

EU326202 Fusarium equiseti DQ166549-Fusarium

DQ166549-Fusarium
CLBE19

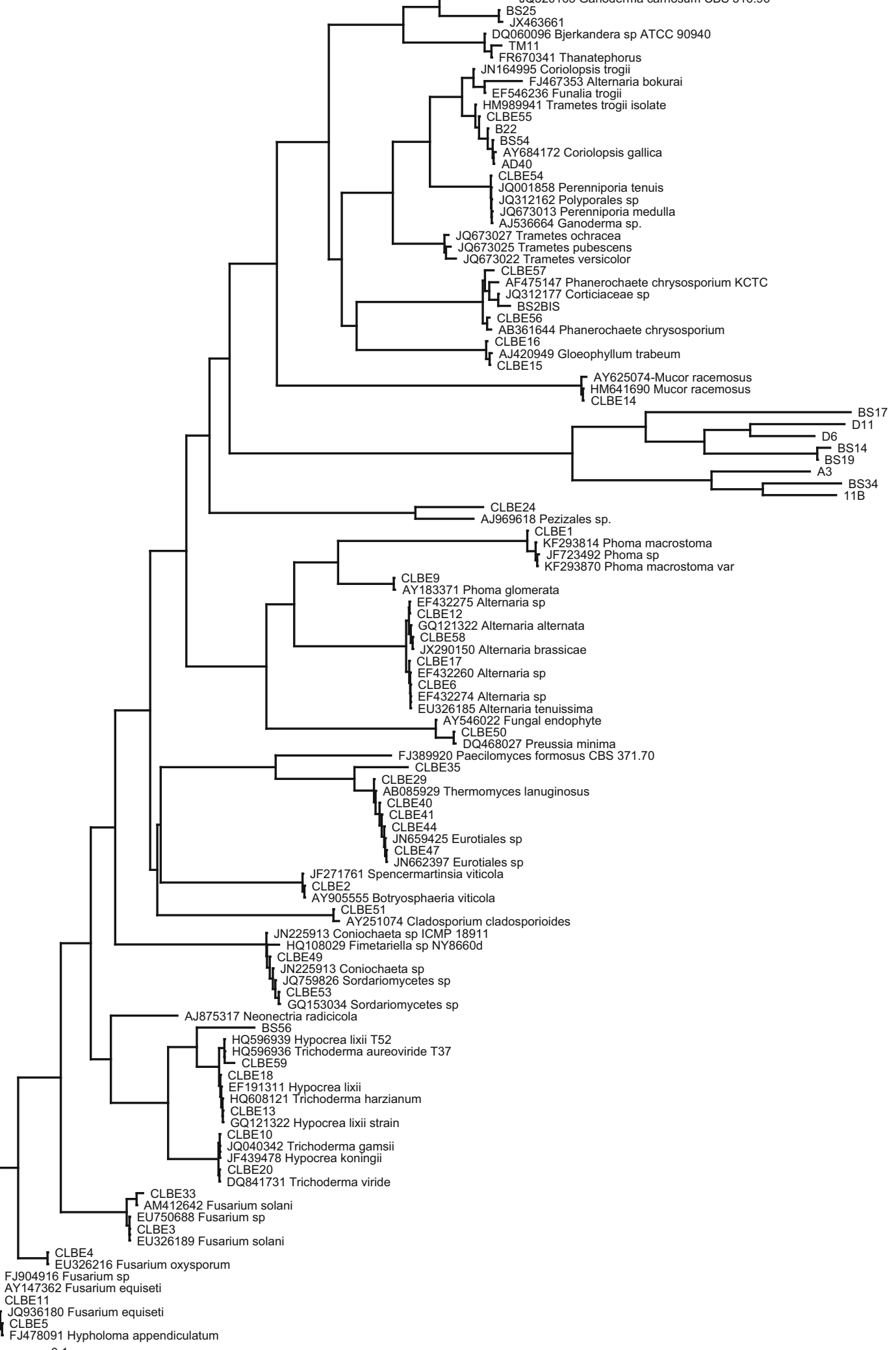

0.1

Fig. 2 continued 
(2007) reported nineteen fungal isolates of the family of Nectriaceae collected from forests in Taiwan.

Additionally, a wide distribution of white-rot fungi throughout basidiomycetes group was also observed (29\%). Within basidiomycetes, the order polyporales was the most represented (25\%) followed by gloeophyllales (4\%). Among wood-rotting fungi, white-rot basidiomycetes are the most efficient in extensive lignin degradation (Blanchette et al. 1992). Brown-rot fungi presented by gloeophyllales order cause also the most destructive type of decay in wooden structures, although their biodegradation mechanisms are still relatively unknown (Schilling et al. 2009).

A general phylogenetic tree was generated with sequences obtained from the amplification of the ITS rDNA region and some sequences from the GenBank database (Fig. 1). Duplicates as well as diverging sequences were deleted to make it possible to draw the tree. It was observed that Polyporales (13 isolates) followed by Pleosporales and Eurotiales (7 isolates each), were the most represented orders in the tree.

Strain BS25 is closely related to $P$. spadiceum (JX463661.1) and Ganoderma carnosum (JQ520163.1) ( $80 \%$ similarity). This suggests that more sampling of environmental fungi and their ITS barcoding is necessary to allow accurate identifications of strains collected in surveys similar to this study. Blast search results showed that many genera such as: Trametes/Coriolopsis, have high similarity in DNA sequences suggesting that phylogenetic analysis is necessary to ascertain the phylogenetic positions of the isolates. Our phylogenetic analysis confirmed the affiliation of most species using ClustalW for alignment and Neighbour joining (Fig. 2).

Figure 2 presents the phylogenetic affinities of 51 Tunisian isolates with some closely related taxa retrieved from GenBank. Our phylogeny confirms a close relationship of BS54, AD 40, CLBE55 and BS22 species to the members of the genus Coriolopsis. Despite a very close similarity in DNA sequences and phylogenetic affiliation to C. trogii (CLBE55, AD40 and BS22), BS54 are confirmed to be Coriolopsis gallica. The genus Coriolopsis, as currently defined, is polyphyletic, with the type species as part of the Trametoid clade and at least two additional lineages occurring in the core polyporoid clade.

\section{Conclusions}

Our findings contribute to the discovery of new fungal strains involved in lignocellulose degradation. The isolated strains are diverse and show a wide spectrum of species demonstrating the wide biodiversity of Tunisian forests. The newly isolated fungal strains belong to different taxonomic groups with various enzymatic activities: amylases, proteases, lipases and laccases, making their further study very interesting for industrial and environmental applications. Our results show that this new collection of isolates had a certain lignin degradation capacity and provide a new resource of microorganisms for dye decolorization.

Acknowledgments The authors are grateful to $\mathrm{Mr}$ Abdelmajid Dammak from the National school of engineering of Sfax for revising the English language of the paper. This project received funding from the European Union's Seventh Framework Programme for research, technological development and demonstration under Grant Agreement No. 245268 (to L.B.). This study was also supported by the SwissBOL project, financed by the Swiss Federal Office for the Environment (Grant holder L.B.), the Swiss State Secretariat for Education and Research (L.B. Grant Reference: SER No. C09.0139), and the European Union for the COST action FP0801 "Established and Emerging Phytophthora: Increasing Threats to Woodland and Forest Ecosystems in Europe".

\section{Compliance with ethical standards}

Conflict of interest This paper declare that they have no conflict of interest.

Open Access This article is distributed under the terms of the Creative Commons Attribution 4.0 International License (http:// creativecommons.org/licenses/by/4.0/), which permits unrestricted use, distribution, and reproduction in any medium, provided you give appropriate credit to the original author(s) and the source, provide a link to the Creative Commons license, and indicate if changes were made.

\section{References}

Ashrafi SD, Rezaei S, Forootanfar H, Mahvi AH, Faramarzi MA (2013) The enzymatic decolorization and detoxification of synthetic dyes by the laccase from a soil-isolated ascomycete, Paraconiothyrium variabile. Int Biodeterior Biodegrad 85:173-181

Barriuso J, Prieto A, Martínez MJ (2013) Fungal genomes mining to discover novel sterol esterases and lipases as catalysts. BMC Genom 14:712

Blanchette RA, Burnes TA, Eerdmans MM, Akhtar M (1992) Evaluating isolates of Phanerochaete chrysosporium and Ceriporiopsis subvermispora for use in biological pulping processes. Holzforschung 46:109-115

Caporale C, Garzillo AM, Caruso C, Buinocore V (1996) Characterization of extracellular proteases from Trametes troggi. Phytochemistry 41:385-393

Cheong S, Yeo S, Song H-G, Choi HT (2006) Determination of laccase gene expression during degradation of 2,4,6-trinitrotoluene and its catabolic intermediates in Trametes versicolor. Microbiol Res 161:316-320

Cho NS, Wilkolazka AJ, Staszczak M, Cho HY, Ohga S (2009) The role of laccase from white rot fungi to stress conditions. J Fac Agr Kyushu Univ 54:81-83

Choi YS, Kim JJ, Kim MJ, Imamura Y, Yoshimura T, Kim GH (2012) Fungal biodegradation of CCA-treated wood and removal of its metal components. Chemosphere 88:725-729

Choi YS, Seo JY, Lee H, Yoo J, Jung J, Kim JJ, Kim GH (2014) Decolorization and detoxification of wastewater containing industrial dyes by Bjerkandera adusta KUC9065. Water Air soil Pollut 225:1-10 
Colao M, Garzillo Ch, Buonocore AM, Schiesser VA, Ruzzi M (2003) Primary structure and transcription analysis of a laccaseencoding gene from the basidiomycete Trametes trogii. Appl Microbiol Biotechnol 63:153-158

Colussi F, Serpa V, Delabona PDS, Manzine LR, Voltatodio ML, Alves R, Mello BL, Pereira N Jr, Farinas CS, Golubev AM, Santos MA, Polikarpov I (2011) Purification, and biochemical and biophysical characterization of cellobiohydrolase I from Trichoderma harzianum IOC 3844. J Microbiol Biotechnol 21:808-817

Cruz-Ramírez MG, Rivera-Ríos JM, Téllez-Jurado A, Maqueda Gálvez AP, Mercado-Flores Y, Arana-Cuenca A (2012) Screening for thermotolerant ligninolytic fungi with laccase, lipase, and protease activity isolated in Mexico. J Environ Manag 95:S256S259

Daâssi D, Frikha F, Zouari-Mechichi H, Belbahri L, Woodward S, Mechichi T (2012) Application of response surface methodology to optimize decolourization of dyes by the laccase-mediator system. J Environ Manag 108:84-91

Daâssi D, Mechichi T, Nasri M, Rodríguez-Couto S (2013) Decolorization of the metal textile dye Lanaset Grey $\mathrm{G}$ by immobilized white-rot fungi. J Environ Manag 129:324-332

Dashtban M, Schraft H, Syed TA, Qin W (2010) Fungal biodegradation and enzymatic modification of lignin. Int J Biochem Mol Biol 1:36-50

Dass SB, Dosoretz CG, Reddy CA, Grethlein HE (1995) Extracellular proteases produced by the wood-degrading fungus Phanerochaete chrysosporium under ligninolytic and non-ligninolytic conditions. Arch Microbiol 163:254-258

de Castro AM, Ferreira MC, da Cruz JC, Pedro KC, Carvalho DF, Leite SG, Pereira N (2010) High-yield endoglucanase production by Trichoderma Harzianum IOC-3844 cultivated in pretreated sugarcane mill byproduct. Enzyme Res 2010:854526

Diwaniyan S, Kharb D, Raghukumar C, Kuhad RC (2010) Decolorization of synthetic dyes and textile effluents by basidiomycetous fungi. Water Air soil Pollut 210:409-419

Eriksson K-EL, Blanchette RA, Ander P (1990) Microbial and enzymatic degradation of wood components. Springer, Berlin, p 397

Fackler K, Gradinger C, Hinterstoisser B, Messner K, Schwanninger M (2006) Lignin degradation by white rot fungi on spruce wood shavings during short-time solid-state fermentations monitored by near infrared spectroscopy. Enzyme Microbial Technol 39:1476-1483

Gnanasalomi VDV, Gnanadoss JJ (2013) Molecular characterization and phylogenetic analysis of laccase producing fungal isolates with dye decolourizing potential. Res Biotechnol 4:01-08

Gomaa OM (2012) Ethanol induced response in Phanerochaete chrysosporium and its role in the decolorization of triarylmethane dye. Ann Microbiol 62:1403-1409

Guu JR, Ju YM, Hsieh HJ (2007) Nectriaceous fungi collected from forests in Taiwan. Bot Stud 48:187-203

Hatakka A (1994) Lignin-modifying enzymes from selected Whiterot fungi-production and role in lignin degradation. FEMS Microbiol Rev 13:125-135

Hatakka A, Hammel KE (2010) Fungal biodegradation of lignocelluloses. In: Hofrichter M (ed) The mycota X industrial applications. Springer, Berlin, pp 319-340

Hawksworth DL (2001) The magnitude of fungal diversity: the 1.5 million species estimate revisited. Mycol Res 105:1422-1432

Hussain A, Shrivastav A, Jain SK, Baghel RK, Rani S, Agrawale MK (2012) Cellulolytic enzymatic activity of soft rot filamentous fungi Paecilomyces variotii. Adv Biores 3:10-17

Jallouli R, Khrouf F, Fendri A, Mechichi T, Gargouri Y, Bezzine S (2012) Purification and biochemical characterization of a novel alkaline (Phospho)lipase from a newly isolated Fusarium solani strain. Appl Biochem Biotechnol 168:2330-2343

Khlifi R, Sayadi S, Belbahri L, Woodward S, Mechichi T (2009) Effect of HBT on the stability of laccase during the decolourization of textile wastewaters. J Chem Technol Biotechnol 84:1828-1833

Kiiskinen LL, Viikari L, Kruus K (2002) Purification and characterisation of a novel laccase from the ascomycete Melanocarpus albomyces. Appl Microbiol Biotechnol 59:198-204

Kiiskinen LL, Ratto M, Kruus K (2004) Screening for novel laccaseproducing microbes. J Appl Microbiol 97:640-646

Kouker G, Jaeger KE (1987) Specific and sensitive plate assay for bacterial lipases. Appl Environ Microbiol 53:211-213

Kovalenko GA, Beklemishev AB, Perminova LV, Chuenko TV, Ivanov ID, Moiseenkov SI, Kuznetsov VL (2013) Recombinant strain producing thermostable lipase from Thermomyces lanuginosus immobilized into nanocarbon silica matrices and properties of the prepared biocatalyzers. Prikl Biokhim Mikrobiol 49:301-311

Lee H, Jang Y, Kim JM, Kim GH, Kim JJ (2013) White-rot fungus Merulius tremellosus KUC9161 identified as an effective degrader of polycyclic aromatic hydrocarbons. J Basic Microbiol 53:195-199

Leonowicz A, Matuszewska A, Luterek J, Ziegenhagen D, WojtasWasilewska M, Cho NS, Hofrichter M (1999) Biodegradation of lignin by white-rot fungi. Fungal Genet Biol 27:175-185

Li S, Gao H, Zhang J, Li Y, Peng B, Zhou Z (2011) Determination of insecticides in water using in situhalide exchange reactionassisted ionic liquid dispersive liquid-liquid microextraction followed by high-performance liquid chromatography. J Sep Sci 34:3178-3185

Ljungdahl LG (2008) The cellulase/hemicellulase system of the anaerobic fungus Orpinomyces PC-2 and aspects of its applied use. Ann N Y Acad Sci 1125:308-321

Ma L, Zhuo R, Liu H, Yu D, Jiang M, Zhang X, Yang Y (2014) Efficient decolorization and detoxification of the sulfonated azo dye Reactive Orange 16 and simulated textile wastewater containing Reactive Orange 16 by the white-rot fungus Ganoderma sp. En3 isolated from the forest of Tzu-chin Mountain in China. Biochem Eng J 82:1-9

Machado KMG, Matheus DR, Bononi VLR (2005) Ligninolytic enzymes production and Remazol Brilliant Blue $\mathrm{R}$ decolorization by tropical Brazilian basidiomycetes fungi. Braz J Microbiol $36: 246-252$

Martínez AT, Speranza M, Ruiz-Dueñas J, Ferreira P, Camarero S, Guillén F, Martínez MJ, Gutiérrez A, del Río JC (2005) Biodegradation of lignocellulosics: microbial, chemical, and enzymatic aspects of the fungal attack of lignin. Int Microbiol 8:195-204

Martínez AT, Ruiz-Dueñas FJ, Martínez MJ, del Río JC, Gutiérrez A (2009) Enzymatic delignification of plant cell wall: from nature to mill. Curr Opin Biotechnol 20:348-357

Mayerhofer HJ, Marshall RT, White CH, Lu M (1973) Characterization of a heat stable protease of Pseudomonas fluorescens $P 23$. Appl Microbiol 25:44-48

Michelin M, Silva TM, Benassi VM, Peixoto-Nogueira SC, Moraes LA, Leão JM, Jorge JA, Terenzi HF, Polizeli Mde L (2010) Purification and characterization of a thermostable $\alpha$-amylase produced by the fungus Paecilomyces variotii. Carbohydr Res 345:2348-2353

Michelotti S, Guglielmo F, Gonthier P (2012) Detection of the wood decay ascomycete Kretzschmaria deusta in urban maple trees in Italy. J Plant Pathol 94:85-105

Moldes D, Cadena EM, Vidal T (2010) Biobleaching of eucalypt kraft pulp with a two laccase-mediator stages sequence. Bioresour Technol 101:6924-6929 
Nilsson T, Daniel G (1989) Chemistry and microscopy of wood decay by some higher ascomycetes. Holzforschung 43:11-18

Obruca S, Marova I, Matouskova P, Haronikova A, Lichnova A (2012) Production of lignocellulose-degrading enzymes employing Fusarium solani F-552. Folia Microbiol 57:221-227

Orth AB, Tien M (1995) Biotechnology of lignin degradation. In: Esser K, Lemke PA (eds) The mycota. II. Genetics and biotechnology. Springer, Berlin, pp 287-302

Peláez F, Martínez MJ, Martínez AT (1995) Screening of 68 species of basidiomycetes for enzymes involved in lignin degradation. Mycol Res 99:37-42

Reddy CA (1995) The potential for white-rot fungi in the treatment of pollutants. Curr Opin Biotechnol 6:320-328

Rossello Mora R, Amman R (2001) The species concept for prokaryotes. Microbiol Res 25:39-67

Ruiz-Dueñas FJ, Martínez AT (2009) Microbial degradation of lignin: how a bulky recalcitrant polymer is efficiently recycled in nature and how we can take advantage of this. Microbial Biotechnol 2:164-177

Ryu WY, Jang MY, Cho MH (2003) The selective visualization of lignin peroxidase, manganese peroxidase and laccase, produced by white rot fungi on solid media. Biotechnol Bioprocess Eng $8: 130-134$

Saitou N, Nei M (1987) The neighbor-joining method: a new method for reconstructing phylogenetic trees. Mol Biol Evol 4:406-425

Sakthivel M, Karthikeyan N, Jayaveny R, Palani P (2010) Optimization of culture conditions for the production of extracellular cellulase from Corynebacterium lipophiloflavum. J Ecobiotechnol 2:6-13

Sato A, Watanabe T, Watanabe Y, Harazono K, Fukatsu T (2002) Screening for basidiomycetous fungi capable of degrading 2,7dichlorodibenzo-p-dioxin. FEMS Microbiol Lett 213:213-217

Schilling JS, Tewalt JP, Duncan SM (2009) Synergy between pretreatment lignocellulose modifications and saccharification efficiency in two brown rot fungal systems. Appl Microbiol Biotechnol 84:465-475

Schoemarker HE (1990) On the chemistry of lignin degradation. Recl Trav Chim Pays Bas 109:255-272

Schoemarker HE, Tuor U, Muheim A, Schmidt HWH, Leisola MSA (1991) White-rot degradation of lignin and xenobiotics. In: Betts WB (ed) Biodegradation natural and synthetic materials. Springer, London, pp 157-174

Selvam K, Shanmuga Priya M, Sivaraj C, Arungandhi K (2012) Identification and Screening of wood rot fungi from Western Ghats area of South India. Int J Chem Tech Res 4:379-388
Shimada M, Higuchi T (1991) Microbial, enzymatic and biomimetic degradation of lignin. In: Hon DNS, Shiraishi N (eds) Wood and cellulosic chemistry. Marcel Dekker, New York, pp 557-619

Sigoillot JC, Berrin JG, Bey M, Lesage-Meessen L, Levasseur A, Lomascolo A, Record E, Uzan-Boukhris E (2012) Fungal strategies for lignin degradation. Adv Bot Res 61:263-308

Silva CMMS, Melo IS, Oliveira PR (2005) Ligninolytic enzyme production by Ganoderma spp. Enzyme Microb Technol 37:324-329

Singh NGKP, Modi DR (2013) Screening of soil fungi for $\alpha$-amylase activity. J Recent Adv Appl Sci 28:110-112

Staszczak M, Nowak G (1984) Proteinase pattern in Trametes versicolor in response to carbon and nitrogen starvation. Biochem J 31:431-437

Sugano Y (2009) DyP-type peroxidases comprise a novel heme peroxidase family. Cell Mol Life Sci 66:1387-1403

Taylor JW (1995) Making the Deuteromycota redundant: a practical integration of mitosporic and meiosporic fungi. Can J 73:754-759

Thompson JD, Higgins DG, Gibson TJ (1994) CLUSTAL W: improving the sensitivity of progressive multiple sequence alignment through sequence weighting, position-specific gap penalties and weight matrix choice. Nucleic Acids Res 22:4673-4680

Thurston CF (1994) The structure and function of fungal laccase. Microbiology 140:19-26

Tigini V, Spina F, Romagnolo A, Progione V, Varese GC (2013) Effective biological treatment of landfill leachates by means of selected white rot fungi. Chem Eng Trans 32:265-270

Xiao P, Mori T, Kondo R (2011) Biotransformation of the organochlorine pesticide trans-chlordane by wood-rot fungi. New Biotechnol 29:107-115

Xiong X, Wen C, Bai Y, Oian Y (2008) Effects of culture conditions on ligninolytic enzymes and proteases production by Phanerochaete chrysosporium in air. J Environ Sci China 20:94-100

Yoon JJ, Cha CJ, Kim YS, Son DW, Kim YK (2007) The brown-rot basidiomycete Fomitopsis palustris has the endo-glucanases capable of degrading microcrystalline cellulose. J Microbiol Biotechnol 17:800-805

Zouari-Mechichi H, Mechichi T, Dhouib A, Sayadi S, Martınez AT, Martınez MJ (2006) Laccase purification and characterization from Trametes trogii isolated in Tunisia: decolorization of textile dyes by the purified enzyme. Enzyme Microb Technol 39:141-148 